\title{
O atendimento à parada cardiorrespiratória em unidade coronariana segundo o Protocolo Utstein*
}

\author{
Assistance of cardiopulmonary arrest in the coronary care unit according to Utstein protocol \\ La atención para parar cardiorrespiratória en la unidad coronariana según el protocolo Utstein
}

Tatiana de Medeiros Colletti Cavalcante', Rita Simone Lopes $^{2}$

\begin{abstract}
RESUMO
Objetivos: registrar os esforços de ressuscitação cardiopulmonar (RCP) conforme o preconizado pelo protocolo de registro de Utstein e apresentar os resultados de acordo com o recomendado pelo mesmo. Métodos: estudo de natureza exploratório-descritiva de 30 esforços ressuscitatórios realizados na Unidade Coronariana do HSP entre Agosto à Dezembro de 2003. Resultados: Dos 30 pacientes estudados $56.66 \%$ eram do sexo masculino, com média de idade de 64.5 anos. A modalidade mais freqüente foi a Atividade Elétrica Sem Pulso. Do total de pacientes, treze $(43.33 \%)$ retornaram a circulação espontânea, porém somente quatro destes mantiveram-se vivos até o término da pesquisa. Conclusão: Em $90 \%$ dos prontuários, os registros apresentavam-se incompletos demonstrando a necessidade de um registro único e sistematizado para RCP, no intuito de melhorar os registros para uma melhor organização do serviço e realização de pesquisas, além de prevenir dispustas éticas e legais.
\end{abstract}

Descritores: Parada cardíaca; Avaliação em Enfermagem.

\begin{abstract}
Objectives: to describe the use of the Utstein protocol in the assistance of cardiopulmonary resuscitation. Methods: This was a descriptive and exploratory study of 30 cardiopulmonary arrests in the Coronary Care Unit of the Hospital São Paulo from August to December 2003. Results: $56.66 \%$ of patients who had cardiopulmonary arrest were male with an average of 64.5 years of age. The pulseless electric activity was the most common presentation. Thirteen patients (43.33\%) returned to spontaneous circulation, but only four of these patients remained alive until the ending of the research. Conclusions: the majority (90\%) of patients' medical records had incomplete documentation showing the need to establish a systematic way to document cardiopulmonary arrest. This may improve the quality of documentation and prevent legal and ethical disputes.
\end{abstract}

Keywords: Heart Arrest; Nursing assessment.

\section{RESUMEN}

Objetivos: registrar los esfuerzos de resucitación cardiopulmonar (RCP) conforme preconizado por el protocolo de registro de Utstein y presentar los resultados de acuerdo con sus recomendaciones. Métodos: estudio de naturaleza exploratoria-descriptiva de 30 esfuerzos de resucitación realizados en la Unidad Coronaria del HSP entre Agosto y Diciembre del 2003. Resultados: De los 30 pacientes estudiados $56.66 \%$ eran del sexo masculino, con un promedio de edad de 64.5 años. La modalidad más frecuente fue la Actividad Eléctrica Sin Pulso. Del total de pacientes, trece (43.33\%) retornaron a la circulación espontánea, sin embargo solamente cuatro de éstos se mantuvieron vivos hasta finalizar la investigación. Conclusión: En el 90\% de las historias clínicas, los registros se presentaban incompletos demostrando la necesidad de un registro único y sistematizado para la RCP, con la intención de mejorar los registros para una mejor organización del servicio y realización de investigaciones, más allá del punto de vista ético legal.

Descriptores: Paro cardíaco; Evaluación en enfermería.

\footnotetext{
* Realizado na Unidade Coronariana do Hospital São Paulo (SP), Brasil.

${ }^{1}$ Especialista em Cardiologia modalidade Residência pela Universidade Federal de São Paulo - UNIFESP - São Paulo (SP) - Brasil

${ }^{2}$ Mestre em ciências aplicadas a cardiologia. Docente substituta do departamento de Enfermagem da Universidade Federal de São Paulo - UNIFESP - São Paulo (SP) - Brasil
} 


\section{INTRODUÇÃO}

A parada cardiorrespiratória (PCR) pode ser definida como uma condição súbita e inesperada de deficiência absoluta de oxigenação tissular, seja por ineficiência circulatória ou por cessação da função respiratória ${ }^{(1)}$.

Estudos sobre a ressuscitação cardiopulmonar dentro do ambiente hospitalar têm demonstrado a efetividade das manobras de ressuscitação, com significativo número de pacientes recebendo alta.

A partir daí, numerosos estudos surgiram sobre a eficácia do atendimento a parada cardiorrespiratória e fatores prognósticos têm sido realizados. Até hoje poucas intervenções na ressuscitação são baseadas em dados científicos válidos ${ }^{(2)}$. As características dos pacientes hospitalizados e seus fatores prognósticos têm sido estudados em diferentes países, com diferentes populações de pacientes e definições distintas de variáveis na reanimação. Alguns autores afirmam que o local demográfico, causas do colapso e outros fatores podem afetar o resultado da reanimação ${ }^{(3)}$. Eles ainda demonstram que a incidência de parada cardiorrespiratória por arritmia ventricular é baixa em países orientais, pois a prevalência de doenças cardíacas isquêmicas no oriente é baixa.

A incidência de ressuscitação cardiorrespiratória em pacientes hospitalizados não é tão simples quando comparada com a PCR extra-hospitalar. Isso porque as doenças pré-existentes nos pacientes hospitalizados podem predizer pior prognóstico. Fatores tais como situação préparada, tempo de início para reanimação e ritmo inicial têm sido demonstrados como preditores de sobrevivência em pacientes hospitalizados em estudos já realizados ${ }^{(4)}$.

Por muito tempo foi difícil comparar dados entre essas pesquisas, pois a nomenclatura não era uniforme e nem mesmo as definições de sucesso ou sobrevida eram as mesmas. No início dos anos 90 este problema foi percebido, e em 1997 surgiu o protocolo de registro de Utstein intra-hospitalar que contempla uma série de dados desejáveis para coleta de informações, definição de sobrevida, entre outros.

O modelo Utstein para registrar paradas cardíacas surgiu na conferência de 1990, na antiga cidade desse nome, numa ilha perto de Stavanger, Noruega, com participação de representantes da American Heart Association (AHA), do Conselho Europeu de Ressuscitação (ERC), a Heart and Stroke Foundation of Canadá (HSFC), o Conselho Sul Africano de Ressuscitação e o Conselho Australiano de Ressuscitação. $\mathrm{Na}$ ocasião, havia a preocupação com uma comparação adequada entre os resultados dos esforços relacionados com ressuscitação, efetuados tanto em diferentes países, como dentro de um mesmo país, por falta de definições e metodologias uniformes. A partir de então, muitos investigadores e diretores de sistemas têm adotado as planilhas, estilo e nomenclatura Utstein para registrar os resultados das manobras de ressuscitação préhospitalar. O êxito desta iniciativa propiciou a padronização dos modelos internacionais para registrar os resultados da ressuscitação pediátrica ${ }^{(5)}$ e para a ressuscitação experimental (laboratorial) ${ }^{(6)}$.

Esse processo de padronização de registro teve prosseguimento com a inclusão da ressuscitação intrahospitalar do adulto, dentro dos acordos internacionais para seu registro. Tais pautas e recomendações podem melhorar o desenho científico dos projetos de investigação e aumentam a utilidade clínica dos estudos publicados ${ }^{(7)}$, de forma a proporcionar evidências consistentes e confiáveis, nas quais se poderão basear as decisões dos tratamentos.

Diante desta realidade, objetivamos com este estudo utilizar o protocolo de registro de Utstein nos atendimentos de PCR, que ocorrem em uma unidade coronariana de um hospital escola e demonstrar os resultados conforme o recomendado pelo protocolo. Assim, poderemos avaliar este procedimento de acordo com as recomendações internacionais e fazermos um paralelo com a realidade encontrada em nosso país, e mais especificamente em nosso serviço.

\section{OBJETIVOS}

Aplicar o protocolo de registro de Utstein nos atendimentos de parada cardiorrespiratória que ocorreram em uma unidade coronariana e apresentar os resultados conforme o referido protocolo.

\section{MÉTODOS}

Trata-se de um estudo de natureza exploratóriodescritiva, com uma abordagem quantitativa. O estudo foi realizado na Unidade Coronariana de um hospital terciário, de grande porte, universitário, localizado na região metropolitana de São Paulo, Brasil.

O universo desta pesquisa foi constituído por 33 pacientes que apresentaram parada cardiorrespiratória em regime de internação hospitalar no referido setor. Destes, três pacientes foram considerados fora de possibilidades terapêuticas, e as manobras de ressuscitação não foram iniciadas, portanto, a RCP foi iniciada em 30 pacientes.

A amostra foi formada por indivíduos de ambos os sexos e diferentes faixas etárias, e teve os seguintes critérios de inclusão: ter tido pelo menos um episódio de parada cardiopulmonar e estar internado na Unidade Coronariana. Foram excluídos deste estudo: pacientes que não tiveram PCR presenciada, e pacientes cuja ficha do protocolo de atendimento à PCR não foi preenchida por profissional treinado.

Os dados foram coletados pela pesquisadora e enfermeiras treinadas para o preenchimento do protocolo de registro durante a internação dos pacientes no período 
de Julho a Novembro de 2003, no momento da parada cardiorrespiratória e associados com informações contidas nos prontuários destes pacientes. Tais dados eram referentes a PCR e alta hospitalar, visto que todos os pacientes foram acompanhados do momento da PCR até o momento da alta hospitalar, mesmo após serem transferidos da Unidade Coronariana.

Todos os dados foram colhidos a partir do momento em que ocorria uma parada cardiorrespiratória testemunhada a qual foi definida quando algum membro da equipe de saúde presenciava o momento da perda da consciência.

A coleta foi instrumentalizada pelo protocolo de registro de Utstein (Anexo 1), onde as variáveis estudadas pelo referido protocolo são: identificação do paciente, dispositivos pré-existentes na parada, condições clínicas antes e após o evento, causas imediatas, tentativa de ressuscitação, ritmo inicial, horário dos eventos associados à PCR, drogas utilizadas, variáveis de seguimento e mortalidade.

Quanto ao horário dos eventos foram considerados os intervalos "Gold Standard": hora do reconhecimento, hora do início da RCP, hora da primeira desfibrilação, hora da intubação, hora da primeira adrenalina, hora da primeira atropina e hora do término da RCP com o desfecho final: retorno à circulação espontânea ou óbito. Com relação à sobrevida, os seguintes dados foram coletados: circulação espontânea por menos de 20 minutos, de 20 minutos a 24 horas e por mais de 24 horas, alta hospitalar e escala de coma de Glasgow na alta hospitalar. Os pacientes que sobreviveram ao episódio de PCR foram acompanhados até o momento da alta hospitalar onde foram submetidos ao exame neurológico clínico completo para determinação de déficits neurológicos após a PCR. Todos estes dados foram coletados e analisados conforme o recomendado pelo protocolo de Utstein ${ }^{(2,5-7)}$.

O estudo foi submetido e aprovado pelo comitê de ética do hospital sem a necessidade de consentimento informado pelo paciente devido às características do estudo.

Os resultados foram apresentados e analisados de forma descritiva e interpretativa sob a forma de gráficos.

\section{RESULTADOS}

No período do estudo, 30 pacientes apresentaram parada cardiorrespiratória. Quanto ao sexo, 17 (56,66\%) eram homens e $13(43,33 \%)$ mulheres com idades variando de 19 a 93 anos, com média de 64,5 anos. A faixa etária mais acometida pela situação em estudo foi de $66-70$ anos $(30 \%)$.

A figura 2 sumariza as doenças de base que levaram à internação os pacientes submetidos à ressucitação cardiopulmonar. A doença de base mais comum foi o Infarto Agudo do Miocárdio (IAM) ocorrido em 13 (43\%) dos pacientes, seguido por arritmias primárias em $5(17 \%)$ e angina instável em $3(10 \%)$ pacientes.

Com relação aos dispositivos existentes ou em uso, no momento pré-parada cardíaca, detectamos que 15 (50\%) dos pacientes tinham acesso venoso central, 10 (33\%) acesso venoso periférico, 04 (13\%) tinham acesso venoso periférico

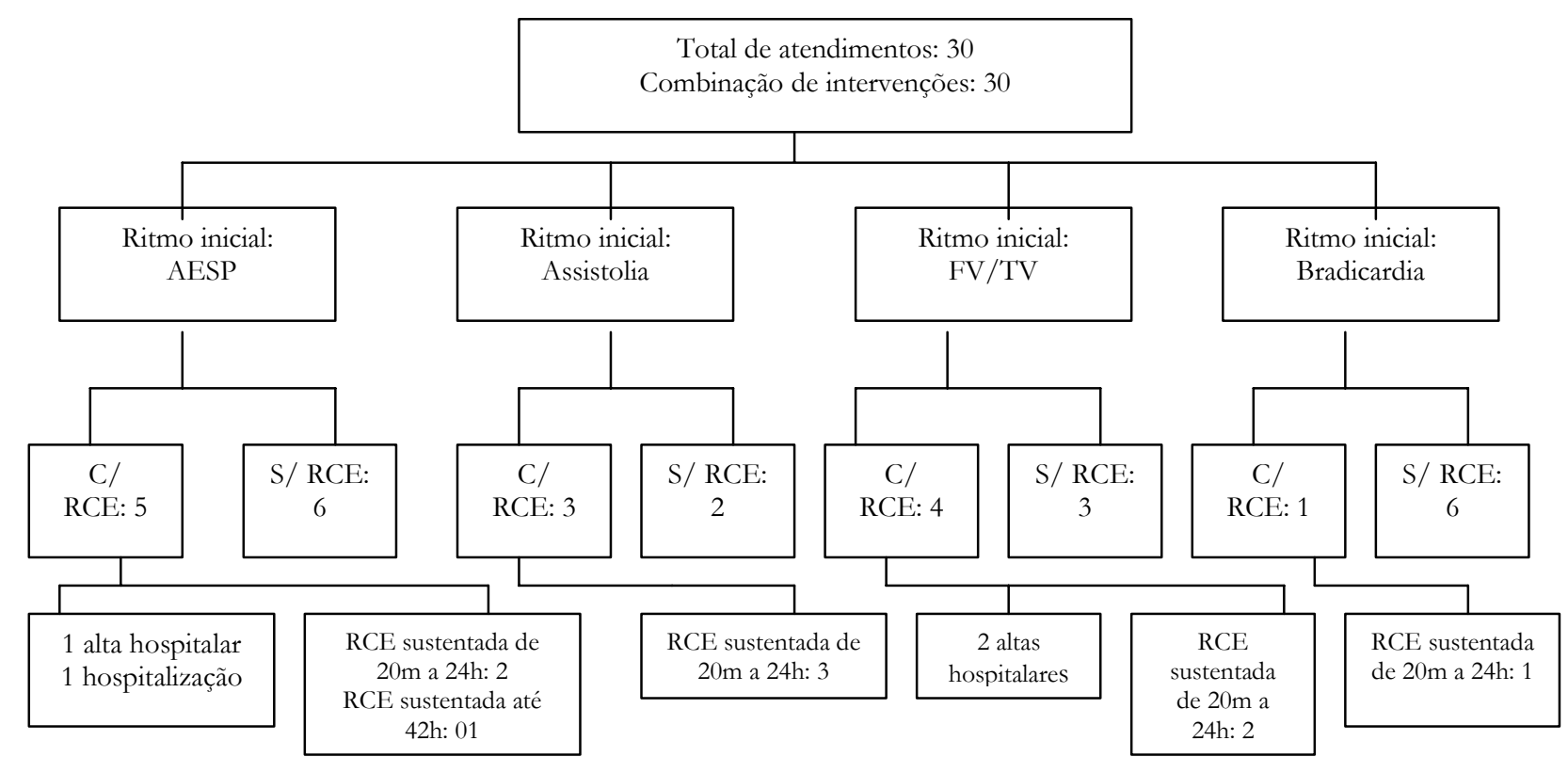

Figura 1 - Resultados do Registro Utstein dos pacientes que sofreram PCR na Unidade Coronariana do Hospital São Paulo. São Paulo, 2003. 
e central, $21(70 \%)$ faziam uso de drogas vasoativas, $3(10 \%)$ usavam drogas antiarritmicas, 17 (57\%) estavam entubados e fazendo uso de ventilação mecânica, $5(17 \%)$ tinham cateter arterial, $3(10 \%)$ usavam marcapasso transvenoso, 2 (3\%) Swan-Ganz e 1 (3\%) balão intra-aórtico, o que demonstra a gravidade da população estudada.

Figura 1-Distribuição percentual das idades entre os pacientes submetidos à reanimação cardiopulmonar. São Paulo, 2003.

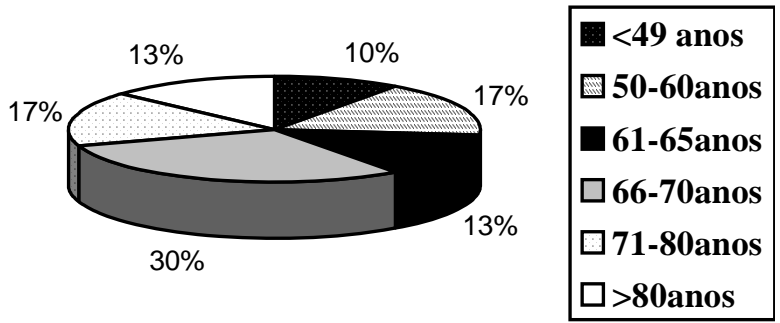

Figura 2 - Doenças de base dos pacientes que sofreram PCR na Unidade Coronariana do Hospital São Paulo. São Paulo, 2003.

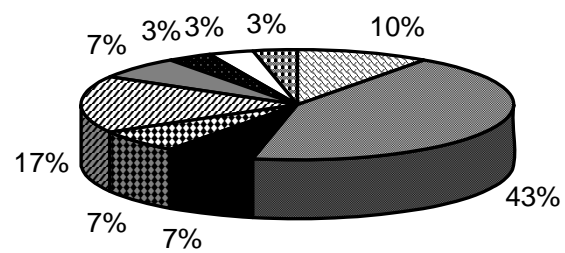

\begin{tabular}{|c|c|c|}
\hline ه Angina Instável & EIAM & $\square \mathrm{ICC}$ \\
\hline 团 ICC+Válvula & 田Arritmias & $\square$ PCR prévias \\
\hline EAP & $\square$ POT TX cardíaco & 國 MCP isquêmica \\
\hline
\end{tabular}

Figura 3 - Causas imediatas de parada cardiorrespiratória em pacientes internados na Unidade Coronariana do Hospital São Paulo. São Paulo, 2003

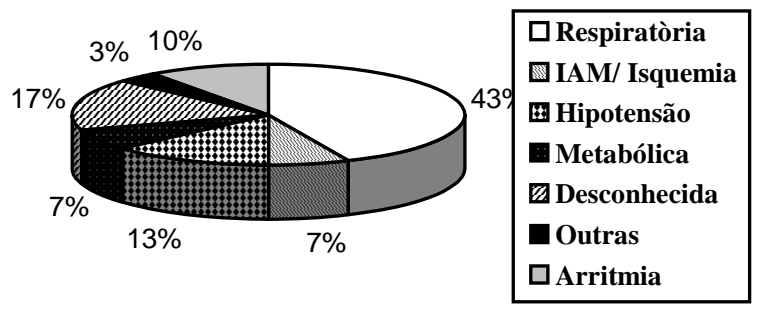

Quanto às causas determinantes imediatas da Parada cardiorrespiratória (Figura 3), a causa respiratória predominou, ocorrida em $13(43 \%)$ dos pacientes, seguida pela causa indefinida em 5 (17\%), pela hipotensão 4 (13\%), pela arritmia primária em 3 (10\%), pelo Infarto Agudo do Miocárdio (IAM) ou isquemia em $2(7 \%)$, pela causa metabólica em $2(7 \%)$ e outras causas em 1 (3\%) paciente, que neste caso envolveu um sangramento profuso.

Figura 4 - Modalidade inicial da parada cardiorrespiratória em pacientes internados na Unidade Coronariana do Hospital São Paulo. São Paulo, 2003

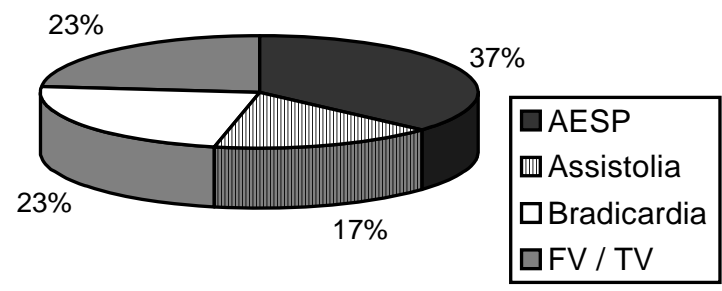

Foi possível determinar-se a modalidade inicial da parada cardiorrespiratória em todos pacientes (Figura 4). Apesar do ritmo inicial em muitos casos se degenerar para outra modalidade de ritmo, neste estudo consideramos apenas o inicial. A atividade elétrica sem pulso (AESP) ocorreu em 11 (37\%) pacientes, a fibrilação ou taquicardia ventricular em 7 (23\%), a bradicardia em $7(23 \%)$ e a assistolia em $05(17 \%)$ pacientes.

A ressucitação cardiopulmonar foi iniciada em até 2 minutos da parada cardiorrespiratória em 100\% dos casos. Sobre os intervalos "Gold-Standard", estes só puderam ser apreciados nos casos em que as enfermeiras treinadas em preencher a ficha de registro do protocolo de Utstein assim o fizeram, pois os dados registrados em prontuários apresentavam-se incompletos em 27 (90\%) pacientes. Foi observado que o tempo entre a detecção da parada em FV e TV e a $1^{\text {a }}$ desfibrilação foi menos de um minuto, bem como a infusão de adrenalina nos demais casos.

Figura 5 - Duração da RCP em pacientes internados na Unidade Coronariana do Hospital São Paulo. São Paulo, 2003

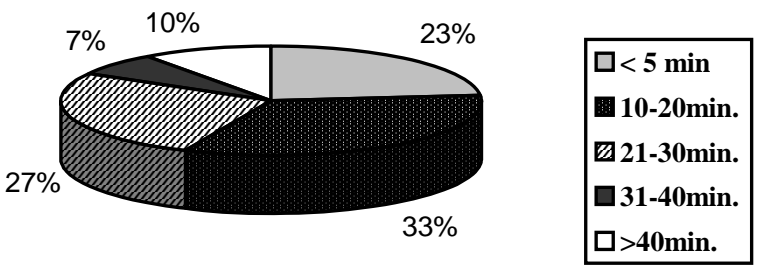


Quanto à duração da ressucitação cardiopulmonar o tempo variou entre 02 e 55 minutos, dependendo do retorno à circulação espontânea ou término dos esforços. $\mathrm{Na}$ Figura 5 fica evidente que a maior porcentagem das reanimações duraram de 10 a 20 minutos.

No grupo de pacientes sobreviventes, $03(75 \%)$ obtiveram alta hospitalar com destino ao domicílio dos mesmos, com escala de Glasgow no momento da alta de 15 . Enquanto que $01(25 \%)$ paciente continua internado há 3 meses após o evento inicial e após ter tido múltiplas paradas, hoje, encontra-se com Glasgow $3 \mathrm{~T}$.

\section{DISCUSSÃO}

Segundo alguns autores, quando a parada cardiorrespiratória ocorre em ambiente hospitalar, tornase mais fácil e rápida a aplicação do suporte básico e avançado de vida ${ }^{(8-9)}$. Por outro lado, quando a parada cardíaca ocorre no ambiente hospitalar ela é freqüentemente associada a importantes doenças e não pode ser comparada com as paradas cardíacas ocorridas fora do hospital ${ }^{(9)}$.

Pesquisadores têm dado uma atenção crescente para o papel do sexo na doença cardiovascular em termos de fatores de risco ${ }^{(10)}$, prognóstico $^{(11)}$ e diferenças no tratamento ${ }^{(12)}$. A força tarefa de Utstein então recomenda a anotação do sexo de todos os pacientes submetidos a RCP.

Mesmo com um predomínio de pacientes do sexo masculino nas pesquisas, também encontrado neste estudo, ainda assim não há diferença estatisticamente significante no que se refere a mortalidade entre os sexos ${ }^{(13-14)}$. Porém, este assunto deve ser mais bem estudado visto que alguns estudos sugerem um melhor prognóstico para mulheres $^{(15-16)}$.

Um dos fatores prognósticos mais estudado é a idade, com resultados bastante divergentes. Este estudo demonstrou pior prognóstico dos pacientes incluídos no extremo da faixa etária. Pacientes acima de 66 anos tiveram um pior prognóstico, o que se encontra de acordo com alguns autores ${ }^{(11,17-18)}$, mas em desacordo com outros ${ }^{(14,19)}$.

A síndrome Coronariana Aguda e as arritmias foram as doenças de base mais freqüentes, tanto no grupo geral, quanto no grupo de pacientes sobreviventes. Outras patologias também se mostraram presentes como a Insuficiência Cardíaca Congestiva (ICC), a associação entre ICC e valvulopatia, entre outras. Esses dados se mostraram semelhantes aos encontrados em outras citações ${ }^{(3,14,20-21)}$, demonstrando que estes pacientes pertencem a um grupo de alto risco, com doença de base mais grave.

Algumas intervenções relacionadas ao suporte avançado de vida podem ser instituídas antes mesmo da parada cardíaca como, por exemplo, a monitorização cardíaca, a intubação orotraqueal com ventilação mecânica, agente intravenosos pressóricos ou inotrópicos ou ainda agentes antiarritmicos, obtenção de acesso venoso periférico e/ou central entre outros. Em nosso estudo detectamos que $83,33 \%$ dos pacientes tinham acesso venoso periférico e/ou central, $70 \%$ faziam uso de drogas vasoativas, $10 \%$ de agentes antiarritmicos, 56,66\% encontravam-se entubados e fazendo uso de ventilação mecânica; $16,66 \%$ tinham cateter arterial, $10 \%$ marcapasso transvenoso, 6,66\% de Swan-Ganz e 3,33\% de balão intraaórtico. Isso por um lado favorece o atendimento à PCR abreviando a tomada de decisão e instituição de medidas

\section{Quadro 1 - Características de pacientes e eventos da PCR pela sobrevida na Unidade Coronariana do} Hospital São Paulo. São Paulo, 2003

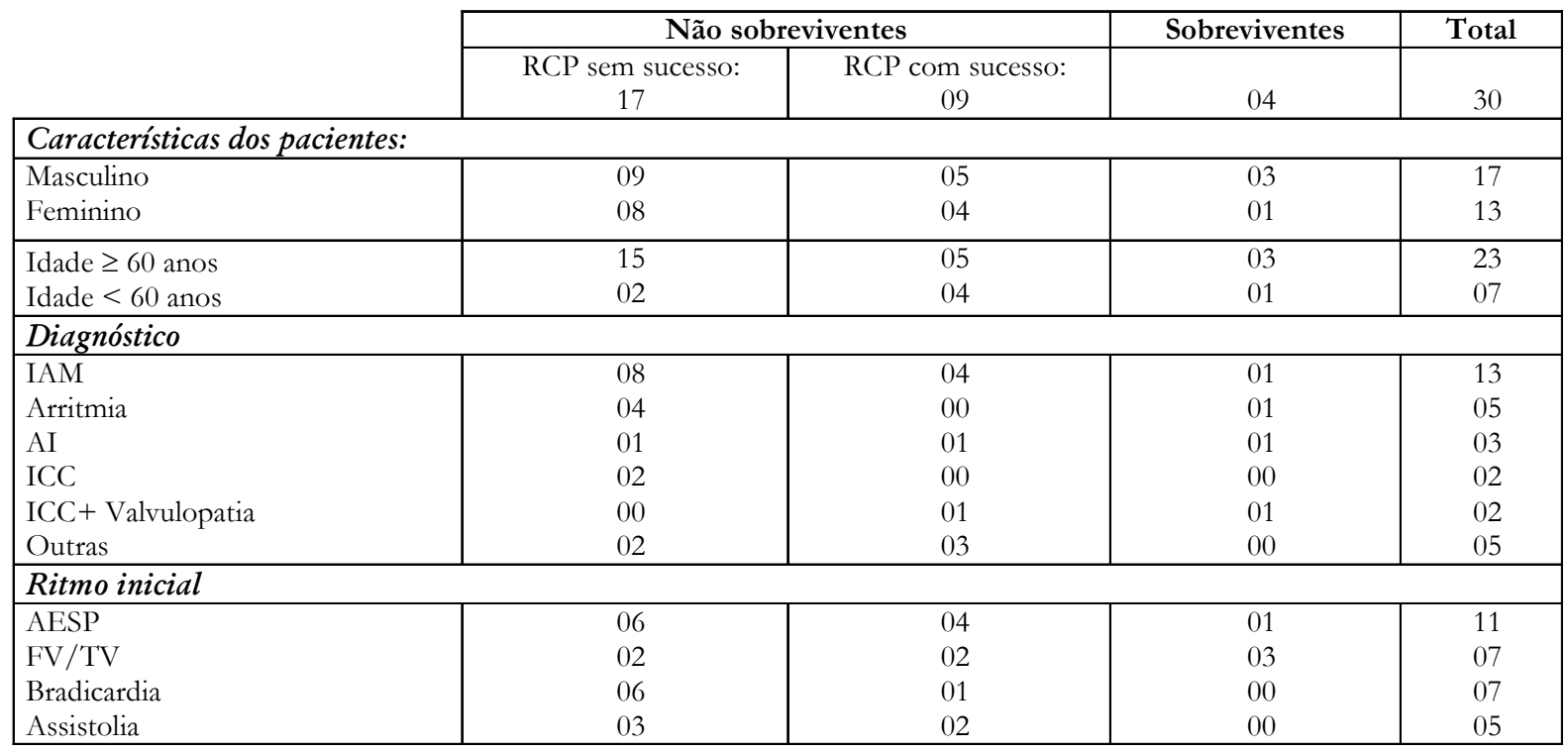


avançadas; porém, por outro lado, estes resultados demonstram a gravidade dos pacientes envolvidos nesta pesquisa. A preexistência de intubação traqueal e uso de ventilação mecânica no momento do evento implica numa diminuição de chance no retorno à circulação espontânea na ressuscitação intra-hospitalar ${ }^{(3)}$.

Quanto à causa determinante imediata da parada cardiorrespiratória, houve um nítido predomínio da causa respiratória em 43,33\% dos pacientes, seguida pela causa desconhecida em 16,66\%, pela hipotensão em 13,33\%, pela arritmia primária em $10 \%$, pelo IAM ou isquemia em $6,66 \%$, causa metabólica em $6,66 \%$ e outras causas em $3,33 \%$. Este dado difere de uma pesquisa ${ }^{(14)}$ que revelou o predomínio de insuficiência miocárdica e arritmia primária. Já a hipotensão aparece como causa determinante em outros estudos ${ }^{(22-23)}$.

O tempo para início da ressusitação cardiopulmonar em todos os casos do estudo foi inferior a 2 minutos, o que confirma os resultados de diversas pesquisas as quais afirmam que o sucesso da ressucitação cardiopulmonar é diretamente proporcional a um breve intervalo de tempo entre o colapso e o início do socorro básico e/ou especializado. Foi observado também que o tempo entre a detecção da parada em FV e TV e a $1^{a}$ desfibrilação foi menor que um minuto, bem como a infusão de adrenalina nos demais casos. Um dado semelhante foi previamente obtido $^{(24-25)}$

O protocolo de Utstein não é implantado na unidade em questão o que dificultou a coleta dos intervalos "gold standard". Esses intervalos só puderam ser determinados quando as enfermeiras da unidade ou a autora da pesquisa preencheram a folha do protocolo, pois ao analisarmos retrospectivamente as anotações em prontuário estas estavam incompletas em $90 \%$ dos casos.

Em um estudo realizado em 2003 a assistolia foi o ritmo mais freqüentemente encontrado (57\%), seguido de FV ou TV em 27\% e AESP em 16\% ${ }^{(26)}$. Em uma amostra prospectiva de 600 pacientes acompanhados, a AESP foi encontrada como ritmo inicial em $48 \%$ dos $\operatorname{casos}^{(27)}$. Em nossa amostra, a AESP foi o ritmo inicial mais freqüentemente encontrado $(36,66 \%)$, seguido de FV / TV (23,33\%), bradicardia (23,33\%) e assistolia $(16,66 \%)$. O estudo realizado por Huang et $\mathrm{al}^{(3)}$ assim como o nosso demonstrou uma baixa incidência de FV/ TV $(13,6 \%)$ como ritmo inicial. O ritmo inicial mais encontrado foi a AESP em $45 \%$ dos casos.

Diferente dos resultados uniformemente observados em relação ao ritmo inicial encontrado nos estudos, que avaliaram a PCR extra-hospitalar, onde a FV ou TV aparece como ritmo inicial em $80-90 \%$ dos casos, os trabalhos que analisam a PCR intra-hospitalar apresentam informações diversas ${ }^{(20,22,24)}$.

Provavelmente, as diferentes características dos hospitais, populações e comorbidades encontradas nos pacientes internados são responsáveis pelos diferentes achados em relação ao ritmo inicial da parada cardiorrespiratória. Em nosso estudo, foram obtidos 43,33\% de reversão inicial após a PCR e 10\% obtiveram alta hospitalar, considerando a taxa de sobrevida em nossa população. Nossos índices estão de acordo quando comparados aos estudos recentes ${ }^{(4,28,29)}$.

A duração entre o colapso e o retorno da circulação espontânea ou término dos esforços variou em nossa pesquisa de 2 a 55 minutos. Este tempo é muito importante para avaliar o prognóstico dos pacientes. Pesquisas revelam que pacientes com PCR maior que 15 minutos tem uma menor chance de sobrevivência ${ }^{(24)}$. Em outra pesquisa, a duração entre o colapso e o retorno à circulação espontânea no grupo sobrevivente foi de 12,6 min, enquanto que no grupo não sobrevivente foi de 16,7 $\min ^{(3)}$. Em nosso estudo a média de tempo no grupo de sobreviventes foi de 6,2 min, enquanto que no grupo de não-sobreviventes foi de 18.4 minutos.

Dos pacientes que retornaram à circulação espontânea e tiveram alta hospitalar, 75\% foram para seu domicílio com Glasgow de 15 e exame neurológico normal, ou seja, sem sinais de lesão neurológica; enquanto que 1 paciente $(25 \%)$ continuava internado em nossa unidade 2 meses após a reanimação e após múltiplas paradas (4 no total) permanecia com Glasgow de 3T e com déficit neurológico importante até o final da coleta de dados.

$\mathrm{O}$ número pequeno de déficit neurológico em nossa amostra é encontrado nas populações atendidas em PCR dentro do ambiente hospitalar e traduz a agilidade no início e na realização de reanimação cardiopulmonar básica, que visa a manutenção da perfusão cerebral enquanto procurase restabelecer um ritmo acompanhado de pulso ${ }^{(29)}$.

\section{CONSIDERAÇÕES FINAIS}

O conhecimento de certas características do paciente que sofre PCR pode nos auxiliar no julgamento da validade da implementação dos esforços ressucitatórios ou de seu abandono.

O ponto principal enfatizado pelo Utstein Style, é o reconhecimento dos tempos de intervenções após a PCR e estabilidade após as medidas terapêuticas para avaliação da eficácia e resposta das vítimas de PCR. Isso é importante para tomá-la como consideração ética e na decisão de ressucitar ou não um paciente.

A identificação de fatores prognósticos dos resultados da RCP pode ser utilizada para apoiar, com base racional, a implementação de uma legislação em nosso meio sobre a decisão de não ressucitar ou de abandonar os esforços ressucitatórios.

A principal dificuldade observada em nossa pesquisa foi a escassez de informações referentes ao atendimento à PCR no prontuário dos pacientes. Sugerimos a 
implantação deste protocolo na unidade em questão para que as informações possam ser colocadas de uma forma completa e consistente no prontuário do paciente atendendo assim às questões éticas, legais e de pesquisa.

Os dados apresentados podem fornecer informações úteis aos médicos que têm que decidir quando começar ou quando terminar com os esforços ressucitatórios. O uso dessas informações pode ajudar a reduzir a tensão imposta pelo paciente e por sua família, bem como os custos que podem resultar do uso de medidas heróicas destinadas a falhar.

\section{REFERENCIAS}

1. Araújo IEM. Ressucitação Cardiorespiratória. In: Cintra EA, Nishide VM, Nunes WA, organizadores. Assistência de enfermagem ao paciente crítico. São Paulo: Atheneu; 2000.

2. Cummins RO, Chamberlain D, Hazinski MF, Nadkarni V, Kloeck W, Kramer E, et al. Recommended guidelines for reviewing, reporting, and conducting research on in-hospital resuscitation: the in-hospital "Utstein style". American Heart Association. Circulation. 1997; 95(8):2213-39.

3. Huang $\mathrm{CH}$, Chen WJ, Ma MH, Chang WT, Lai CL, Lee YT . Factors influencing the outcomes after inhospital resuscitation in Taiwan. Resuscitation. 2002; 53(3): 265-70.

4. Dane FC, Russell-Lindgren KS, Parish DC, Durham MD, Brown TD. In-hospital resuscitation: association between ACLS training and survival to discharge. Resuscitation. 2000; 47(1): 83-7.

5. Zaritsky A, Nadkarni V, Hazinski Mf, Foltin G, Quan L, Wringht J, Fiser D, Zideman D, O'Malley P, Chameides L, American Academy of Pediatrics, (2) American Heart Association and (3) European Resuscitation Council. Recommended guidelines for uniform reporting of pediatric advanced life support: the pediatric Utstein style. Ann Emerg Med. 1995; 26(4): 487-503. Review.

6. Idris AH, Becker LB, Ornato JP, Hedges JR, Bircher NG, Chandra NC, et al. Utstein-style guidelines for uniform reporting of laboratory CPR research. A statement for healthcare professionals from a task force of the American Heart Association, the American College of Emergency Physicians, the American College of Cardiology, the European Resuscitation Council, the Heart and Stroke Foundation of Canada, the Institute of Critical Care Medicine, the Safar Center for Resuscitation Research, and the Society for Academic Emergency Medicine. Writing Group. Circulation. 1996; 94(9): 2324-36. Review.
7. Checklist of information for inclusion in reports of clinical trials. The Asilomar Working Group on Recommendations for Reporting of Clinical Trials in the Biomedical Literature. Ann Intern Med. 1996; 124(8): 741-3.

8. Gullo A. Cardiac arrest, chain of survival and Utstein style. Eur J Anaesthesiol. 2002; 19(9): 624-33. Review.

9. Becker L.B. The epidemiology of Sudden death. In: Paradis NA, Halperin HR, Nowak RM (eds.). Cardiac arrest: the science and practice of resuscitation medicine. Baltimore: Williams \& Wilkins; 1996. p. 93551.

10. Dahlberg ST. Gender difference in the risk factors for sudden cardiac death. Cardiology. 1990;77 Suppl 2: 31-40. Review.

11. Tofler GH, Stone PH, Muller JE, Willich SN, Davis VG, Poole WK, et al. Effects of gender and race on prognosis after myocardial infarction: adverse prognosis for women, particularly black women. J Am Coll Cardiol. 1987; 9(3):473-82.

12. Ayanian JZ, Epstein AM. Differences in the use of procedures between women and men hospitalized for coronary heart disease. N Engl J Med. 1991; 325(4):221-5.

13. Moreira DM, Mariante Neto G, Oliveira MW, Alves LB, Adamatti LCC, Trotta EA, Vieira SRR. Estudo retrospectivo de sobrevida de pacientes submetidos à reanimação cardiorrespiratória em unidade de tratamento intensivo. Arq Bras Cardiol. 2002; 78(6):545-52.

14. Tortolani AJ, Risucci DA, Rosati RJ, Dixon R. Inhospital cardiopulmonary resuscitation: patient, arrest and resuscitation factors associated with survival. Ressucitation. 1990; 20(2): 115-28.

15. Pell JP, Sirel J, Marsden AK, Cobbe SM. Sex differences in outcome following community-based cardiopulmonary arrest. Eur Heart J. 2000; 21(3): 32944.

16. Wigginton JG, Pepe PE, Bedolla JP, Detamble LA, Atkins JM. Sex-related differences in the presentation and outcome of out-of-hospital cardiopulmonary arrest: a multiyear, prospective, population-based study. Crit Care Med. 2002; 30(4 Suppl): S131-6.

17. Dumot JA, Burval DJ, Sprung J, Waters JH, Mraovic B, Karafa MT, et al. Outcome of adult cardiopulmonary resuscitations at a tertiary referral center including results of "limited" resuscitations. Arch Intern Med. 2001; 161(14): 1751-8.

18. Herlitz J, Ekstrom L, Wennerblom B, Axelsson A, Bang A, Holmberg S. Risk indicators for, and symptoms associated with, death among patients hospitalized after out-of-hospital cardiac arrest. Coron Artery Dis. 1994;5(5):407-14.

19. Roberts D, Landolfo K, Light RB, Dobson K. Early 
predictors of mortality for hospitalized patients suffering cardiopulmonary arrest. Chest. 1990; 97(2):413-9.

20. Ballew KA, Philbrick JT, Caven DE, Schorling JB. Predictors of survival following in-hospital cardiopulmonary resuscitation. A moving target. Arch Intern Med. 1994; 154(21):2426-32.

21. Beuret P, Feihl F, Vogt P, Perret A, Romand JA, Perret C. Cardiac arrest: prognostic factors and outcome at one year. Resuscitation. 1993; 25(2):171-9.

22. Rogove HJ, Safar P, Sutton-Tyrrell K, Abramson NS. Old age does not negate good cerebral outcome after cardiopulmonary resuscitation: analyses from the brain resuscitation clinical trials. The Brain Resuscitation Clinical Trial I and II Study Groups. Crit Care Med. 1995; 23(1):18-25.

23. Di Bari M, Chiarlone M, Fumagalli S, Boncinelli L, Tarantini F, Ungar A, et al. Cardiopulmonary resuscitation of older, inhospital patients: immediate efficacy and long-term outcome. Crit Care Med. 2000; 28(7): 2320-5.

24. Skrifvars MB, Rosenberg PH, Finne P, Halonen S, Hautamaki R, Kuosa R, et al. Evaluation of the inhospital Utstein template in cardiopulmonary resuscitation in secondary hospitals. Resuscitation. 2003; 56(3):275-82.

25. Spearpoint KG, McLean CP, Zideman DA. Early defibrillation and the chain of survival in "in-hospital" adult cardiac arrest; minutes count. Resuscitation. 2000; 44(3):165-9.

26. Bartholomay E, Dias FS, Torres FA, Jacobson P, Mariante A, Wainstein R, et al. Impacto das manobras de reanimação cardiorespiratória cerebral em um hospital geral: fatores prognósticos e desfechos. Arq Bras Cardiol. 2003; 81(2): 182-95.

27. Copper S, Cade J. Predicting survival, in-hospital cardiac arrests: resuscitation survival variables and training effectiveness. Resuscitation. 1997; 35(1): 1722.

28. Andreasson AC, Herlitz J, Bang A, Ekstrom L, Lindqvist J, Lundstrom G, Holmberg S. Characteristics and outcome among patients with a suspect in-hospital cardiac arrest. Resuscitation. 1998; 39(1-2):23-31.

29. Herlitz J, Andreasson AC, Bang A, Aune S, Lindqvist J. Long-term prognosis among survivors after inhospital cardiac arrest. Resuscitation. 2000; 45(3): 16771. 


\section{ANEXO 1}

\section{REGISTRO DO ATENDIMENTO A PCR}

\section{IDENTIFICAÇÃO:}

Iniciais:

RG:

Leito: Idade:

Sexo: M ( ) F ( ) Peso: Altura: Admissão: Diagnóstico de internação:

\section{DISPOSITIVOS PRÉ-EXISTENTES NA PARADA}

( ) Nenhum

( ) Acesso venoso: Central ( ) Periférico ( )

( ) Drogas vasoativas

( ) Drogas antiarritmicas

( ) Intubação

( ) Ventilação mecânica

( ) Cateter arterial

( ) Marcapasso: Transcutâneo ( )

Transvenoso ( )

( ) Swan-Ganz ( ) BIA
- Causas imediatas
( ) Arritmia
( ) Respiratória
( ) hipotensão
( ) IAM ou isquemia
( ) Outras
( ) Metabólica
( ) Desconhecida

- Tentada ressucitação:

( ) $\operatorname{Sim}$ ( marque os realizados)

( ) Via aérea ( ) comp.torácica ( ) desfibrilação

( ) Não

( ) achado morto ( ) considerado fútil

$\checkmark \quad$ Ritmo inicial (No caso de mais de um ritmo, enumere-os)

( ) FV ( ) TV ( ) AESP ( ) Bradicardia ( ) Assistolia

\section{HORA DOS EVENTOS}

Parada detectada: Parada confirmada: RCP iniciada:

Via aérea obtida:

Circulação espontânea:

( ) retornou, se sim

( ) Nunca atingida

( ) RCE não sustentada: ( ) $<20$ min. ( ) $>20 \mathrm{~min}<24 \mathrm{~h}($ ) $>24 \mathrm{~h}$

\section{DROGAS UTILIZADAS (mg/amp/vol.)}

Epinefrina:

Procainamida:

Sulf. Magnésio:
Lidocaína:

Amiodarona:

Gluc. Ca: 1a Desfibrilação

1a Dose de epinefrina:

$1^{\text {a }}$ Dose de atropina

RCP terminada

\section{VARIÁVEIS DE SEGUIMENTO}

$\checkmark$ Envolvidos na reanimação: ( ) Médico ( ) Enfermeiro ( ) auxiliar de enf.

$\checkmark \quad \mathrm{N}^{\circ}$ de médicos com ACLS:

$\checkmark \quad \mathrm{N}^{\circ}$ de enfermeiros com ACLS:

$\checkmark$ Quando acordou: data:

$\checkmark$ Seguimento no hospital:

( ) alta Data:

- Destino: ( ) Outro hospital

- Glasgow na alta:

( ) Morte no hospital

hora: _____ Data:

( ) Suporte retirado ( ) Morte cerebral ( ) Doador

Principal causa do óbito:

$\checkmark$ Outras tentativas de reanimação? (Se há mais de 24 horas da atual)

( ) Sim ( ) Não Quantas?

Datas:

$\checkmark$ Dados anotados no prontuário referente à PCR:

( ) Completos ( ) Incompletos

Informações adicionais: 